\title{
$\underline{\text { Great Rehabilitation Nurses Combine Art and Science to Create Magic }}$
}

By: Donald D. Kautz

This is the accepted version of the following article:

Kautz, D.D. (2011). Great rehabilitation nurses combine art and science to create magic. Rehabilitation Nursing, 36(1), 13-24. doi: 10.1002/j.2048-7940.2011.tb00060.x

which has been published in final form at http://dx.doi.org/10.1002/j.20487940.2011.tb00060.x.

\begin{abstract}
***(C) Association of Rehabilitation Nurses. Reprinted with permission. No further reproduction is authorized without written permission from Association of Rehabilitation Nurses \& Wiley. This version of the document is not the version of record. Figures and/or pictures may be missing from this format of the document. ***
\end{abstract}

\section{Abstract:}

I believe that rehabilitation nurses have the potential to create and experience "magic" every day in their practice. Some nurses might be offended by the word "magic" because they associate magic with being dark, secretive, or perhaps evil. The magic to which I am referring encompasses the captivating, powerful, moving, and cherished moments that nurses create and experience.

Keywords: comprehensive pain | management |evidence-based practice | nurse-patient relations | problem patients | rehabilitation nursing | safe patient handling | spinal cord injury

\section{Article:}

Note. This article was the basis for Dr. Kautz's keynote address at the 2010 ARN Educational Conference in Orlando, FL.

I believe that rehabilitation nurses have the potential to create and experience "magic" every day in their practice. Some nurses might be offended by the word "magic" because they associate magic with being dark, secretive, or perhaps evil. The magic to which I am referring encompasses the captivating, powerful, moving, and cherished moments that nurses create and experience.

I have been a rehabilitation nurse for more than 30 years, and I know that great rehabilitation nurses routinely incorporate the art and science of nursing into their practice. No nurse is a "great" nurse all of the time- that would be impossible. But all of us have great moments, and in these moments we combine research-based best practices with our own experiences of working with patients and their families. This is when the magic occurs. I would like to tell you about a time when magic occurred for me and for a patient with whom I was working. 
I was the neuroscience clinical nurse specialist at a tertiary care level 1 trauma center affiliated with a preeminent medical school and university. Sally, who was in her 20s, had become a C5-6 quadriplegic as the result of a vehicular crash. She also had undergone a left upper arm amputation as a result of the crash. She was a married mother of three small children and her home was several hours from the medical center; her family rarely was able to visit. When I first met Sally, she was still in the intensive care unit (ICU), had just been weaned from the ventilator, and was in a halo brace. The ICU nurses asked me to see her because she was extremely anxious and demanding. She also was experiencing severe neck and shoulder pain and phantom pain in her left arm. Because of the halo brace, she could not see the residual limb of her left arm and often complained that the nurses had positioned her so that she was lying on her left wrist and hand. The nurses could see that the arm was gone but Sally could not, and she had very little feeling in either arm other than the pain from her C5-6 injury.

I had worked for years on an acute spinal cord injury rehabilitation unit, so I had learned several interventions that might help Sally. Some interventions were based on science; others I had learned from experience and these skills represented the "art” of being an experienced rehabilitation nurse (Kautz, 2008). Based on my experience, I believed that Sally may cope better if she could be distracted from the horror of being a new quadriplegic and if she could feel more in control of her care (Consortium for Spinal Cord Medicine, 2008). Despite her condition, I knew she could control some aspects of her care. I called the physical therapy department and got her a pair of prism glasses so she could increase her scope of vision and watch television. I believed that as she could see more of what was happening around her, she also would feel more in control of her care. I had learned at an ARN conference that shoulder positioning was a key factor in promoting comfort in new quadriplegics, especially those in a halo brace. I worked with the ICU staff and showed them how they could position her residual limb in different positions using towels and pillows (Fries, 2005). Sally's job was to focus on the best positions for her left stump and right arm when she was on either her right or left side. Sally was a willing participant in these efforts and quickly found that she could stay an hour or two on each side by varying her arm positions.

I also implemented the science of rehabilitation nursing, especially in relieving Sally's pain and anxiety. A new quadriplegic patient experiences three types of acute pains as well as chronic pain over time. Somatic pain (sharp and stabbing) results from the injury and fusion surgery, visceral pain (ache) from immobility, and neuropathic pain (burning and tingling) from the spinal cord injury, all of which require different treatments (Institute for Clinical Systems Improvement, 2009). This acute pain will continue and become chronic pain. I decided it would be best to treat all three types of acute pain, begin treatment for chronic pain, and treat anxiety. I asked the physicians to start her on around-the-clock nonsteroidal anti-inflammatory (NSAID) medications for her pain caused by inflammation and a histamine (H2) blocker to prevent peptic ulcers associated with the NSAID. They also agreed to start her on an around-the-clock small dose of Valium to help with her anxiety and provide additional muscle-relaxant effects. Even 
though Sally still was in spinal shock and did not have spasms, the physicians also agreed to start her on baclofen (Lioresal) so that by the time her spasms started, the medication would have reached a therapeutic level (Birns \& Fitzpatrick, 2008). Amitriptyline (Elavil) was initiated for her neurogenic pain even though it would take several weeks to become effective. The nurses told me in the following days that a "miracle” had occurred for Sally, and that Sally's interventions were "magic."

When I returned to work after being gone for a few days, Sally had been transferred out of the ICU to the general neuroscience nursing unit. As I walked down the hall, I heard Sally calling out a nurse's name. I went in to see her and she said, "Please come here quick, I need you.” I walked over to her bed and she said, "Please scratch my nose, it itches.” Then she said, "The nurses all hate me. They stand outside my room ignoring me and laughing at me.” I had worked with these nurses for some time and knew full well that none of them would do this. I told Sally I would be back in a few minutes, and then I went to the conference room to talk with these nurses. They said that Sally knew all of their voices and would constantly call out to them, even though she had a call ball that she could ring on her own. (A call ball is a call light mechanism placed inside a tennis ball that is suspened by a patient's head, shoulder, or arm so he or she can "bump” it and call the nurse.) After one of them went in, the requests would be for nonpriority tasks such as scratching her itching nose or rearranging her bedside table.

These nurses also told me that they were starting to get Sally up in a wheelchair; while doing so, she would complain of being dizzy and panic, fearing that she was going to fall. I agreed to go in and help her get out of bed and into the wheelchair. Indeed, Sally told me too that she was going to get dizzy and fall. I explained how I would transfer her and told her that I had years of experience transferring patients and knew all the tricks to make her comfortable, so she agreed.

Now I was able to use art and science again. I put on Sally's thromboembolic deterrent (TED) hose and abdominal binder before getting her up. I asked her to take several deep breaths and explained to her that the TED hose, abdominal binder, and deep breaths would combat the orthostatic hypotension (and resulting dizziness) she would experience when transitioning from lying to sitting (Consortium for Spinal Cord Medicine, 2008). Next I raised the head of her bed, talking with her the entire time. She replied with amazement that she was not dizzy. Here it was, another moment of magic. I swung her legs out over the edge of the bed, and she again said she was not dizzy. Then, much to her horror, I transferred her by myself from the bed to her wheelchair using a sliding board. I had assured her several times that I could do this without hurting either of us, but she still panicked and complained throughout the transfer. I got her situated in the partially reclined wheelchair with the arm and feet rests in place and a lapboard across her lap and her right arm comfortably placed. To prevent injury to patients and nurses, the type of transfer I used with Sally is no longer recommended. The current recommendations for turning and transferring patients to prevent nurse injuries are to use evidence-based safe patient handling guidelines (Nelson, Motacki, \& Menzel, 2009; Waters \& Rockefeller, 2010). 
I could not believe her reaction to the transfer. She kept saying over and over, "Help me, I am going to fall. I am falling." The sensation of falling is thought to be caused by the halo brace, which creates a feeling of floating (Consortium of Spinal Cord Medicine, 2008). Only a few things are "certain" in nursing, and one of them is that a C5-6 quadriplegic patient in a halo brace, positioned correctly in a reclining wheelchair (as Sally was), is not going to fall. I pulled a chair up beside her and assured her I was not going anywhere and would sit and talk with her for the entire 30 minutes she was going to sit in the chair. Sitting calmly with anxious patients, listening to their concerns, teaching them about their illness, and showing them new ways to cope can often be helpful (Levigne \& Kautz, 2010). In this case, my calm presence, listening, and assurances did not help. Sally kept repeating, "I am falling, I am falling, I am going to fall. Please, do something ...”.

I don't know how long I sat there reassuring her, but it seemed like an eternity. I started to cry. Sally said, "What's wrong?” I replied, "Sally, you are killing me.” She was taken aback. Then, she started to laugh. This is the first time anyone working with her remembered her laughing. She kept saying, "I am killing you?” and laughed. We talked, and after 30 minutes, I put her back to bed. Her laughing was a turning point for her, and so another moment of magic had occurred.

I came to visit Sally a number of times during the next several days. The nursing staff had begun getting her up several times a day, transferring her to the wheelchair, and taking her outside and to other places she wanted to go. Although her anxiety had decreased, she still was demanding to be turned often and still wanted someone to scratch her nose and perform other tasks. On Thursday, she was transferred to the spinal cord unit at a nearby rehabilitation facility for a comprehensive spinal cord rehabilitation program (I had worked there for many years before coming to the medical center).

I called the rehabilitation facility on Friday afternoon to inquire about how she was doing. I talked to a nurse with whom I had worked for years. She said, "Sally? Sally is not here. Don, I'm ashamed of you. You didn't notice that one thigh was much larger than the other? She has a deep vein thrombosis (DVT). We sent her back to you for heparin therapy.” I hung up the phone. I knew she was not back on the neuroscience unit. After checking, I discovered she had been put on one of the medical floors and her anti-coagulation was being managed by a medical team. I went down and talked with Sally, the medical resident, and the nursing staff about any questions they might have. I also brought Sally a call ball that she could "ring" with her chin so she could call the nurses (Fries, 2005), and then I went home for the weekend.

On Monday, when I came back in, I had some early morning commitments and was not able to get up to the medical floor to see Sally until around 10:30. As I walked down the hall, I saw that the call light above her door was on. "Typical," I thought. I walked into the room, and to my surprise Sally had an elderly roommate. Sally was in the bed farthest from the door and was turned on her side away from the door. I walked around the side of the bed to face her. She said, "Hi. What time is it?” I told her it was 10:30. She said, “Oh, the nurses said they were going to 
come in and turn me at 9:30. They must have gotten busy. Can you do me a favor? Please take Ms. 'Smith' in the next bed to the bathroom." I took Ms. Smith to the bathroom, and then I turned Sally. I said, "Sally, what happened to you? You are not the same person that left here last Thursday." She replied, "When I got to the rehab facility, the first thing they asked me was what my goals for rehab were. I hadn't thought about that. I decided it was time for me to get on with my life. I am a mother. Mothers don't ask for help all the time. Mothers are the ones who do things for others." Another moment of magic! Changing focus from what has been lost to focusing on the future has been identified as a key element in the maintaining of hope for those with new spinal cord injuries (Lohne \& Severinsson, 2004).

I learned lessons from Sally that I continue to use in my practice. First, we all need a change of venue now and then. For Sally, it was transferring to the rehabilitation unit, and then back to the medical unit on the same day. No one on the medical unit knew Sally, and both Sally and her caregivers got a new start. Second, Sally got a roommate. She had someone to focus on other than herself. Sally was a mother who was used to caring for others, and the roommate was just what Sally needed. Finally, we all need goals, and when we help our patients to see their goals, we empower them to create their own future (Kautz, 2008). What magic!

Sally experienced two additional kinds of magic. First, she did not recognize the effect I was having on her. I was the clinical nurse specialist, consulting with the nurses and doctors. The interventions that worked for her were interventions put in place by the nursing staff, not me. I am sure she does not remember me- - why should she? She never really knew who I was. I was just one of the many faces she came into contact with in a sea of caregivers. But even though Sally does not remember me, she changed my life forever. And that is the second piece of magic. Sally did not know the effect she had on me. This is the true magic we create and experience as rehabilitation nurses. We may never know who we have a profound effect on, and, likewise, our patients may never know the life-changing effects they have on us. This magic keeps us coming back to work day after day. My hope in sharing Sally's story is that you will remember your own "Sally," that these memories will remind you why you became a rehabilitation nurse, and the memories will help you remember that you are a great rehabilitation nurse. I also hope that you will continue to use the art and science of rehabilitation nursing every day to create these magical moments. Although we never know when magic might occur, magic will occur more often if we purposefully use art and science every day. And when we share these moments with each other, we create hope for the future of nursing.

\section{Acknowledgments}

The author gratefully acknowledges the editorial assistance of Elizabeth Tornquist with this manuscript.

\section{References}


Birns, J., \& Fitzpatrick, M. (2008). Management of spasticity: A brief overview of educational and pharmacological therapies. British Journal of Neuroscience Nursing, 4, 370373.

Consortium for Spinal Cord Medicine. (2008). Early acute management in adults with spinal cord injury: A clinical practice guideline for health-care professionals. Retrieved October 8, 2010, from www.pva.orgsitePageServerpagenamepubs_mainCPG.

Fries, J. M. (2005). Critical rehabilitation of the patient with spinal cord injury. Critical Care Nursing Quarterly, 28, 179-187.

Institute for Clinical Systems Improvement. (2009). Health care guideline: Assessment and management of chronic pain (4th ed.). Retrieved October 11, 2010, from www.icsi.orgpain_chronic_assessment_and_management_of_14399pain_chronic_asses sment_and_management_of__guideline_.html.

Kautz, D. D. (2008). Inspiring hope in our rehabilitation patients, their families, and ourselves. Rehabilitation Nursing, 33, 148-153, 177.

Levigne, D., \& Kautz, D. (2010). Professional issues: The evidence for listening and teaching may reside in our hearts. MEDSURG Nursing, 19, 194-196.

Lohne, V., \& Severinsson, E. (2004). Hope during the first few months after acute spinal cord injury. Journal of Advanced Nursing, 47,279-286.

Nelson, A., Motacki, K., \& Menzel, N. (2009). Illustrated guide to safe patient handling and movement. Glenview, IL: Association of Rehabilitation Nurses.

Waters, T. R., \& Rockefeller, K. (2010). Safe patient handling for rehabilitation professionals. Rehabilitation Nursing, 35, 216-222. 